\title{
Definition of fields margins for the optimized 2D radiotherapy of prostate carcinoma
}

\author{
MILLY BUWENGE ${ }^{1}$, MARIANGELA PERRONE ${ }^{2}$, GIAMBATTISTA SIEPE $^{1}$, \\ ILARIA CAPOCACCIA ${ }^{1}$, AYNALEM ABRAHA WOLDEMARIAM ${ }^{3}$, TIGENEH WONDEMAGEGNHU ${ }^{3}$, \\ KAMAL A.F.M. UDDIN ${ }^{4}$, MOSTAFA A. SUMON ${ }^{4}$, ELENA GALOFARO ${ }^{1}$, GABRIELLA MACCHIA ${ }^{2}$, \\ FRANCESCO DEODATO ${ }^{2}$, SAVINO CILLA ${ }^{5}$ and ALESSIO G. MORGANTI ${ }^{1}$
}

\begin{abstract}
${ }^{1}$ Radiation Oncology Center, Department of Experimental, Diagnostic and Specialty Medicine-DIMES, University of Bologna, S. Orsola-Malpighi Hospital, I-40138 Bologna; ${ }^{2}$ Radiotherapy Unit, Fondazione di Ricerca e Cura 'Giovanni Paolo II', Catholic University of Sacred Heart, I-86100 Campobasso, Italy; ${ }^{3}$ Department of Radiation Oncology, Black Lion Hospital, 9086 Addis Ababa, Ethiopia; ${ }^{4}$ Radiation Oncology Department, United Hospital Limited, Gulshan, Dhaka 1212, Bangladesh; ${ }^{5}$ Medical Physic Unit, Fondazione di Ricerca e Cura 'Giovanni Paolo II', Catholic University of Sacred Heart, I-86100 Campobasso, Italy
\end{abstract}

Received December 13, 2018; Accepted April 15, 2019

DOI: $10.3892 /$ mco.2019.1855

\begin{abstract}
Prostate cancer (PCa) is one of the most common malignancies in men both in western and developing countries. Radiotherapy (RT) is an important therapeutic option. New technologies (including 3D, intensity modulated RT, image-guided RT and, volumetric modulated arc therapy) have been introduced in the last few decades with progressive improvement of clinical outcomes. However, in many developing countries, the only treatment option is the traditional two-dimensional (2D) technique based on standard simulation. The guidelines for 2D field definition are still based on expert's opinions. The aim of the present study was to propose new practical guidelines for 2D fields definition based on 3D simulation in PCa. A total of 20 patients were enrolled. Computed tomography-simulation and pelvic magnetic resonance images were merged to define the prostate volumes. Clinical Target Volume (CTV) was defined using the European Organisation for Research and Treatment of Cancer guidelines in consideration of the four risk categories: Low, intermediate, and high risk with or without seminal vesicles involvement, respectively. Planning Target Volume (PTV) was defined by adding $10 \mathrm{~mm}$ to the CTV. For each category, two treatment plans were calculated using a cobalt source or $10 \mathrm{MV}$ photons. Progressive optimization was achieved by evaluating 3D
\end{abstract}

Correspondence to: Dr Milly Buwenge, Radiation Oncology Center, Department of Experimental, Diagnostic and Specialty Medicine-DIMES, University of Bologna, S. Orsola-Malpighi Hospital, via Massarenti 9, I-40138 Bologna, Italy

E-mail: mbuwenge@gmail.com

Key words: prostate neoplasms, radiotherapy, 2D, simulation, less resourced departments dose distribution. Finally, the optimal distances between field margins and radiological landmarks (bones and rectum with contrast medium) were defined. The results were reported in tabular form. Both field margins (PTV $\mathrm{D}_{98 \%}>95 \%$ ) needed to adequately irradiate all patients and to achieve a similar result in $95 \%$ of the enrolled patients are reported. Using a group of patients with $\mathrm{PCa}$ and based on a 3D planning analysis, we propose new practical guidelines for PCa 2D-RT based on current criteria for risk category and CTV, and PTV definition.

\section{Introduction}

Prostate cancer (PCa) is one of the most common cancers in males. Current guidelines (NCCN) consider radiation therapy (RT) as a therapeutic option in different disease stages using three-dimensional conformal RT (3D-CRT) and Intensity Modulated RT (IMRT) as the standard techniques (1).

The incidence of $\mathrm{PCa}$ is lower in developing than in western countries. However, a progressive increase in the incidence of $\mathrm{PCa}$ due to the prolonged life expectancy has been recorded (2). Furthermore, available RT technologies in developing countries have several limitations with several centres using only standard simulators and cobalt machines as the treatment planning and delivery technologies, respectively (3-5).

In the past, $\mathrm{PCa}$ irradiation was based on 2D techniques with treatment fields defined with standard simulators $(6,7)$. In the ' 80 s, further population-based indications for 2D-RT arose from the evaluation of prostate size and anatomical location using computed tomography (CT) scans (8). However, nowadays more detailed information and guidelines are available allowing tailored RT even with 2D technology.

In fact, RT of PCa is based on: i) clear guidelines on target definition related to risk categories (9); ii) treatment planning systems (TPS) to enable 3D dose evaluation with possibilities of computing a customized treatment plan for individual 
patients by adapting the beams geometry to different beam energies; iii) the possibility of defining standard irradiation geometries based on 3D dose distribution among a patients population.

Optimized 2D-RT based on these new insights could be helpful for centres without advanced RT technologies (3D-CRT, IMRT).

Based on this background, the purpose of this study was to propose practical guidelines for 2D-RT beams definition adapted to different $\mathrm{PCa}$ risk categories and different available beam energies.

\section{Materials and methods}

From our institution, 20 patients with histological confirmation of PCa, consecutively treated with RT were identified (median age: 72 years; range: $58-77$ years; clinical T stage: cT2b: 3 , cT2c: 5, cT3a: 9, cT3b: 3). Patients underwent CT-simulation in supine position after 3 days of laxatives to avoid rectal distension. Before CT-simulation commencement, $10 \mathrm{cc}$ of contrast medium (Gastrografin) were injected into the rectum. Scans were performed every $5 \mathrm{~mm}$ from $3 \mathrm{~cm}$ below the ischial tuberosities to $3 \mathrm{~cm}$ above the promontory. Patients underwent pelvic MRI scan. MRI images were fused with CT-simulation images by using the VelocityAI system (Velocity Medical Solutions, Atlanta, GA) based on the B-spine algorithm for deformable registrations. In this way, delineation of the prostate and seminal vesicles was performed on MRI images. The delineated targets were then transferred to CT-simulation images for treatment planning.

Clinical Target Volume definition (CTV) was based on the EORTC guidelines (9). Irrespective of the individual patient's tumor stage, CTV delineation was done for four different categories: i) low-risk PCa: CTV = prostate; ii) intermediate-risk PCa: $\mathrm{CTV}=$ prostate $+5 \mathrm{~mm}$ radial margin, with inclusion of the caudal $(1 \mathrm{~cm})$ portion of the seminal vesicles; iii) high-risk PCa without involvement of the seminal vesicles: Prostate + $5 \mathrm{~mm}$ radial margin, with the inclusion of the caudal $(2 \mathrm{~cm})$ portion of the seminal vesicles; iv) high-risk PCa with involvement of seminal vesicles: prostate $+5 \mathrm{~mm}$ radial margin and inclusion of all the seminal vesicles. All contours were verified by an experienced operator and a senior consultant (GM, FD, AGM). Organs at Risk (OaRs) contours were defined according to the QUANTEC indications (10). The Planning Target Volume (PTV) was defined by adding a margin of $10 \mathrm{~mm}$ to the CTV in all directions (11).

For each patient, eight treatment plans were generated. For each of the four risk categories, two box technique treatment plans were calculated using a cobalt source or $10 \mathrm{MV}$ photons. A fixed Source-Axis Distance (SAD) of $100 \mathrm{~cm}$ for Linear Accelerator and $80 \mathrm{~cm}$ for the cobalt unit was used. The beams weights were $20 \%$ (anterior-posterior and posterior-anterior beams) and $30 \%$ (lateral beams) to reduce the dose to the rectum, small bowel, and bladder. Beams were drawn using the standard collimators (without multileaf collimators). Standard collimators were initially placed at $5 \mathrm{~mm}$ distance with respect to the PTV margins. Then the minimum dose (defined as D98\%) was evaluated. Fields sizes were gradually increased in steps of $5 \mathrm{~mm}$ to achieve the minimum PTV dose constraint (D98\% >95\%). This progressive optimization was carried out with an iterative procedure, with several evaluations of cumulative dose/volume histograms and beams eye-view dose paintings. In this way, it was possible to identify the field sizes to be increased based on observed 'cold spots' sites.

Once the final plan was achieved, distances of the field edges from a set of reference points (Tables I-IV) were measured. Both the maximum and the 95th percentile of the distances were identified. The latter value was taken as the 'recommended' value for radiation fields margin.

The study was approved by the institutional board High Technology Center for Research and Education-Ethical Committee (Campobasso, Italy) and it is registered in an international public registry (ClinicalTrials.gov Identifier: NCT03339531). Written informed consent was obtained from all of the enrolled patients for the use of their images in this study prior to the analysis.

\section{Results}

Tables I-IV show the results of the analysis in terms of fields margins from radiological landmarks margins in the various patient's categories: Low risk, intermediate risk, high risk, and high risk with involvement of seminal vesicles. Both the field margins needed to adequately irradiate all patients of the analysed sample and distances sufficient to achieve the same result in $95 \%$ of the enrolled patients are reported. The latter dimensions were defined as the 'recommended' margins. Figs. 1 and 2 show the distances to be considered between fields margins and the radiological landmarks.

\section{Discussion}

A planning study on real patients' population was performed to suggest personalized treatment margins for 2D-RT. A box technique was used because it is easy to plan with a conventional simulator and dose conformity produced to the target. Furthermore, previous analysis showed that this technique produces planning results comparable to those achieved with more complex techniques (e.g., 6 beams) (12). Definition of anatomical structures like seminal vesicles and prostate apex location was performed with pelvic MRI co-registration. This integration was used based on the advantages of MRI in prostatic target definition as previously clearly demonstrated (13). Particularly, a study of Villeirs and colleagues showed that the fusion of MRI and CT in PCa contouring results in a moderate decrease of the CTV but a relevant decrease of inter-observer variation especially at the prostate apex (14).

Before CT-simulation, a small amount of contrast medium was injected into the rectum. This preparation although not required for CT-simulation was used to attain the same conditions for conventional simulation. In fact, the purpose of this study was to provide practical guidelines for this planning method. CTV to PTV margin of $10 \mathrm{~mm}$ was used based on a randomized trial which demonstrated that this margin produces the same clinical results compared to larger margins (11). This result was confirmed by Creak and colleagues who reported no evidence of a difference in PSA control according to CTV to PTV margin (1 cm vs. $1.5 \mathrm{~cm})(15)$. It must be acknowledged that CTV to PTV margin lower than one centimetre is currently used. However, we considered this margin 
Table I. Field definition: Low risk prostate cancer.

Treatment machine

\begin{tabular}{|c|c|c|c|c|}
\hline Field & Margin & Description & Cobalt 60 & 10 MV LINAC \\
\hline \multirow[t]{3}{*}{ Anterior-posterior } & Lateral & From the center of the symphisis pubis (laterally) $[\mathrm{A}]$ & $5.7(5.7)$ & $4.5(5.0)$ \\
\hline & Inferior & From the bottom of ischial tuberosities (above) [B] & $0.9(0.9)$ & $1.4(1.8)$ \\
\hline & Superior & From the top of the symphisis pubis (above) $[\mathrm{C}]$ & $5.4(6.7)$ & $4.9(5.7)$ \\
\hline \multirow[t]{4}{*}{ Lateral } & Anterior & From the posterior margin of the symphisis pubis (posteriorly) [D] & $0.3(0.4)$ & $0.4(0.5)$ \\
\hline & Posterior & From the most anterior point of the rectum (posteriorly) $[\mathrm{E}]$ & $4.7(5.9)$ & $3.3(3.7)$ \\
\hline & Inferior & From the bottom of ischial tuberosities (above) & $0.9(0.9)$ & $1.4(1.8)$ \\
\hline & Superior & From the top of the symphisis pubis (above) & $5.4(6.7)$ & $4.9(5.7)$ \\
\hline
\end{tabular}

Reported measures represent the minimal individual field margins needed to respect the constraint $\mathrm{D}_{98}$ (minimal dose) $>95 \%$. Measures are expressed in $\mathrm{cm}$. Indicated measures (those not in brackets) represent the 95th percentile of the measured distances (recommended margins). The values presented in round brackets indicate the maximum measured distances. The letters presented in square brackets correspond to the letter indicators in Figs. 1 and 2.

Table II. Field definition: Intermediate risk prostate cancer.

\begin{tabular}{|c|c|c|c|c|}
\hline \multirow[b]{2}{*}{ Field } & \multirow[b]{2}{*}{ Margin } & \multirow[b]{2}{*}{ Description } & \multicolumn{2}{|c|}{ Treatment machine } \\
\hline & & & Cobalt 60 & 10 MV LINAC \\
\hline \multirow[t]{3}{*}{ Anterior-posterior } & Lateral & From the center of the symphisis pubis (laterally) [A] & $6.2(6.8)$ & $5.2(5.5)$ \\
\hline & Inferior & From the bottom of ischial tuberosities (above) [B] & $0.5(1.0)$ & $1.3(1.4)$ \\
\hline & Superior & From the top of the symphisis pubis (above) [C] & $5.5(7.9)$ & $5.0(6.3)$ \\
\hline \multirow[t]{4}{*}{ Lateral } & Anterior & From the posterior margin of the symphisis pubis (posteriorly) [D] & $0.3(0.4)$ & $0.3(0.4)$ \\
\hline & Posterior & From the most anterior point of the rectum (posteriorly) $[\mathrm{E}]$ & $4.9(6.0)$ & $3.8(4.2)$ \\
\hline & Inferior & From the bottom of ischial tuberosities (above) & $0.5(1.0)$ & $1.3(1.4)$ \\
\hline & Superior & From the top of the symphisis pubis (above) & $5.5(7.9)$ & $5.0(6.3)$ \\
\hline
\end{tabular}

Reported measures represent the minimal individual field margins needed to respect the constraint $\mathrm{D}_{98}$ (minimal dose) $>95 \%$. Measures are expressed in $\mathrm{cm}$. Indicated measures (those not in brackets) represent the 95th percentile of the measured distances (recommended margins). The values presented in round brackets indicate the maximum measured distances. The letters presented in square brackets correspond to the letter indicators in Figs. 1 and 2.

appropriate being that our suggestions are mostly addressed to centres without electronic portal imaging devices or more advanced image-guided technologies.

In this analysis, irradiation beams of different energies were simulated including beams produced by a cobalt machine. We must recognize that the use of cobalt machines is currently considered obsolete especially for PCa treatment. However, in many developing countries RT departments it is the only available treatment device $(3,4)$. The possibility of effective dose delivery with this type of treatment unit respecting the current dose/volume constraints remains uncertain. In particular, it is doubtful the possibility of an effective delivery to high tumor dose with safe OaRs irradiation using the box technique despite its practical advantages. It is generally believed that using only 4 beams, the delivery of $>60$ Gy doses is impossible without reaching an excessive dosage to superficial tissues. In fact, $\mathrm{PCa}$ treatment with cobalt machines was often performed with rotational techniques. However, we still included in this analysis also irradiation with a cobalt machine due to the following reasons: i) Doses lower than the ones currently considered standard (>70-75 Gy) (i) may still be useful in post-operative treatment; (ii) some randomized studies showed a significant biochemical and clinical benefit by delivering $60 \mathrm{~Gy}$ to the prostatic bed (16-18); ii) lower standard doses might still be effective if combined with androgen deprivation therapy (ADT); several randomized studies demonstrated a significant advantage in terms of specific or overall survival by combining ADT to RT at lower doses (65-70 Gy) than those currently considered as standards (>70-75 Gy) (19-23);

iii) the current recommended 'standard doses' were defined mainly based on biochemical relapse-free survival advantage and not in terms of overall survival $(11,24-28)$; the use of high doses in other words was less associated with a significant improvement of 'clinical' outcomes;

iv) in addition, a meta-analysis including 7 randomized clinical trials compared the results achieved with conventional RT dose and high-dose RT. The latter resulted significantly associated with improved biochemical control but there was 
Table III. Field definition: High-risk prostate cancer.

Treatment machine

Fields Margin Description

Cobalt $6010 \mathrm{MV}$ LINAC

\begin{tabular}{lllll}
\hline Anterior-posterior & Lateral & From the center of the symphisis pubis (laterally) [A] & $7.1(9.0)$ & $5.7(5.8)$ \\
& Inferior & From the bottom of ischial tuberosities (above) [B] & $0.4(0.8)$ & $1.3(1.3)$ \\
& Superior & From the top of the symphisis pubis (above) [C] & $7.6(9.3)$ & $5.1(6.9)$ \\
Lateral & Anterior & From the posterior margin of the symphisis pubis (posteriorly) $[\mathrm{D}]$ & $0.3(0.3)$ & $0.3(0.4)$ \\
& Posterior & From the most anterior point of the rectum (posteriorly) [E] & $6.2(8.0)$ & $4.4(4.8)$ \\
& Inferior & From the bottom of ischial tuberosities (above) & $0.4(0.8)$ & $1.3(1.3)$ \\
& Superior & From the top of the symphisis pubis (above) & $7.6(9.3)$ & $5.1(6.9)$
\end{tabular}

Reported measures represent the minimal individual field margins needed to respect the constraint $\mathrm{D}_{98}$ (minimal dose) $>95 \%$. Measures are expressed in $\mathrm{cm}$. Indicated measures (those not in brackets) represent the 95th percentile of the measured distances (recommended margins). The values presented in round brackets indicate the maximum measured distances. The letters presented in square brackets correspond to the letter indicators in Figs. 1 and 2.

Table IV. Field definition: High-risk prostate cancer with seminal vesicle involvement.

\begin{tabular}{|c|c|c|c|c|}
\hline \multirow[b]{2}{*}{ Fields } & \multirow[b]{2}{*}{ Margin } & \multirow[b]{2}{*}{ Description } & \multicolumn{2}{|c|}{ Treatment machine } \\
\hline & & & Cobalt 60 & 10 MV LINAC \\
\hline \multirow[t]{3}{*}{ Anterior-posterior } & Lateral & From the center of the symphisis pubis (laterally) [A] & $7.7(9.8)$ & $6.7(6.9)$ \\
\hline & Inferior & From the bottom of ischial tuberosities (above) [B] & $0.4(0.6)$ & $1.0(1.3)$ \\
\hline & Superior & From the top of the symphisis pubis (above) $[\mathrm{C}]$ & $8.7(9.1)$ & $6.6(7.3)$ \\
\hline \multirow[t]{4}{*}{ Lateral } & Anterior & From the posterior margin of the symphisis pubis (posteriorly) [D] & $0.3(0.4)$ & $0.3(0.4)$ \\
\hline & Posterior & From the most anterior point of the rectum (posteriorly) $[\mathrm{E}]$ & $6.7(8.1)$ & $5.1(6.0)$ \\
\hline & Inferior & From the bottom of ischial tuberosities (above) & $0.4(0.6)$ & $1.0(1.3)$ \\
\hline & Superior & From the top of the symphisis pubis (above) & $8.7(9.1)$ & $6.6(7.3)$ \\
\hline
\end{tabular}

Reported measures represent the minimal individual field margins needed to respect the constraint $\mathrm{D}_{98}$ (minimal dose) $>95 \%$. Measures are expressed in $\mathrm{cm}$. Indicated measures (those not in brackets) represent the 95th percentile of the measured distances (recommended margins). The values presented in round brackets indicate the maximum measured distances. The letters presented in square brackets correspond to the letter indicators in Figs. 1 and 2.

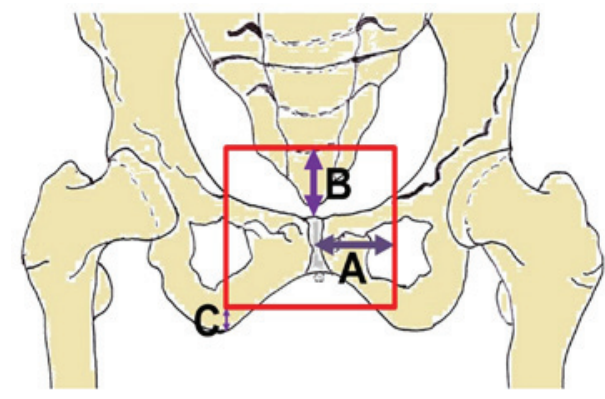

Figure 1. Position and direction of the margins indicated in the tables (on the anterior field). 'A' indicates the distance between the lateral field margin and the center of the symphysis pubis; ' $\mathrm{B}$ ' indicates the distance between the inferior margin of the field and the bottom of ischial tuberosities; and ' $C$ ' indicates the distance between the superior field margin and the top of the symphysis pubis.

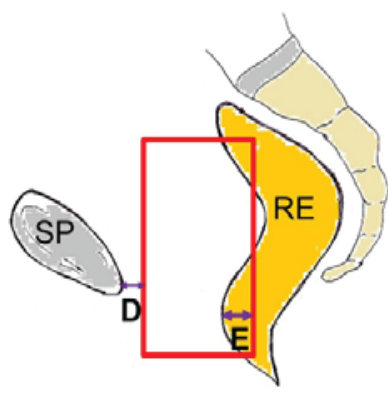

Figure 2. Position and direction of the margins indicated in the tables (on the lateral fields). RE, rectum; SP, symphysis pubis; 'D', distance between the anterior field margin and the posterior margin of the symphysis pubis; 'E', the distance between posterior field margin and the most anterior point of the rectal wall. no difference in terms of mortality rate and specific prostate cancer mortality rate. Furthermore, a subgroup analysis showed that a dose of $64 \mathrm{~Gy}$ is associated with a 5-year biochemical relapse-free survival of 72,61 and $40 \%$ in low, intermediate and high-risk PCa, respectively (29). Obviously, these results cannot be defined as optimal but may be acceptable in health 
systems where other alternative therapies or RT techniques are not available.

In our analysis we have not dealt with the problem of OaRs and planning organ at risk volumes. The main reason is that using a 2D-RT technique it is not possible to calculate the DVHs and to evaluate the constraints of OaRs including planning organ at risk volumes. However, the technique proposed by us is intended to be used with relatively low doses (60-64 Gy). In accordance to the QUANTEC, the maximum bladder dose should be less than 65 Gy and the $\mathrm{V}_{65}$ Gy of the rectum must be less than $25 \%$, it is reasonably likely that these constraints are respected. Guidelines for PCa 2D-RT were obviously available in the past. However, these were mainly based on 'expert's opinion' or population-based CT measurements of prostate and seminal vesicles $(6,8)$. Our study presents obvious differences in terms of: i) precise MRI-based prostate and seminal vesicles contouring; ii) use of an additional margin between prostate and CTV according to risk category; iii) CTV to PTV margin validated by the results of a clinical trial (11); iv) definition of field margins adapted to different energy beams.

Probably in clinical practice it is possible to further optimize our instructions by customizing them to individual patients even with 2D technology. These optimizations can be implemented with simple diagnostic integrations feasible with a standard simulator.

Use of retrograde urethrography and cystography for example could enable an individualized location of the prostate apex and base, respectively $(30,31)$. In addition, it should be noted that the recommended margins in our study are based on the 95th percentile of the obtained measurement. This means that they may be considered adequate in $95 \%$ of patients. This choice derives from the need to obtain a compromise between tumor control probability and the risk of side effects. However, in the tables also the maximum value of the measured distance, i.e. the sizes appropriate in $100 \%$ of the evaluated sample was indicated. Therefore, in case of simulation images showing a reduced OaRs involvement, the planner can use the larger value to increase the likelihood of complete target 'coverage'. Although the limits of PCa irradiation with a cobalt machine have been previously mentioned, this analysis represents the basis for a subsequent study that has been planned in our center with the aim of defining the dose which can be safely administered with this kind of machine. The study will be conducted based on the current OaRs dose/volume constraints (10).

Our study was limited to prostate $+/$ - seminal vesicles irradiation. However, according to current guidelines in high-risk patients, prophylactic irradiation of the pelvic lymph nodes is recommended (1). Therefore, a further study was planned to provide $2 \mathrm{D}$ indications for pelvic fields design based on current guidelines for nodal CTV definition (32).In conclusion, we aimed at providing convenient 2D PCa target delineation tools. In the last years, our team worked on the optimization of 2D-RT in palliative treatments (33-35). Worth noting is that 2D-RT is still in use in several centers in the world. Therefore, we think that other similar studies based on advanced radiological technologies could be performed to optimize 2D-RT techniques in other tumors for less equipped departments.

\section{Acknowledgements}

Not applicable.

\section{Funding}

No funding was received.

\section{Availability of data and materials}

All data generated or analyzed during the present study are included in this published article.

\section{Authors' contributions}

MB, SC, FD, GM, TW, KAFMU, MAS and AGM conceived and designed the present study. SC, MB, MP, EG, GS, IC, AAW and AGM planned the treatments, and analyzed and interpreted the data. MB, FD, IC, AAW, GM, TW, KAFMU, MAS and AGM drafted the article. IC, AAW, TW, KAFMU, MAS and AGM critically revised the manuscript for important intellectual content. All authors have read and approved the final manuscript.

\section{Ethics approval and consent to participate}

The present study was approved by the institutional board High Technology Center for Research and Education-Ethical Committee (Campobasso, Italy), and it is registered in an international public registry (ClinicalTrials.gov Identifier: NCT03339531). Written informed consent was obtained from all of the enrolled patients for the use of their images in this study prior to the analysis.

\section{Patient consent for publication}

Not applicable.

\section{Competing interests}

The authors declare that they have no competing interests.

\section{References}

1. Mohler J, Bahnson RR, Boston B, Busby JE, D'Amico A, Eastham JA, Enke CA, George D, Horwitz EM, Huben RP, et al: NCCN clinical practice guidelines in oncology: Prostate cancer. J Natl Compr Canc Netw 8: 162-200, 2010.

2. Adebamowo CA and Akarolo-Anthony S: Cancer in Africa: Opportunities for collaborative research and training. Afr J Med Med Sci (38 Suppl 2): S5-S13, 2009.

3. Barton MB, Frommer M and Shafiq J: Role of radiotherapy in cancer control in low-income and middle-income countries. Lancet Oncol 7: 584-595, 2006.

4. Kigula Mugambe JB and Wegoye P: Pattern and experience with cancers treated with the Chinese GWGP80 cobalt unit at Mulago Hospital, Kampala. East Afr Med J 77: 523-525, 2000.

5. Page BR, Hudson AD, Brown DW, Shulman AC, Abdel-Wahab M, Fisher BJ and Patel S: Cobalt, linac, or other: What is the best solution for radiation therapy in developing countries? Int $\mathbf{J}$ Radiat Oncol Biol Phys 89: 476-480, 2014.

6. Zelefsky MJ, Valicenti RK, Hunt M and Perez CA: Low-risk prostate cancer. In: Perez and Brady's Principles and Practice of Radiation Oncology. Halperin EC, Perez CA, Brady LW, Wazer DE, Freeman C and Prosnitz LR (eds). 5th edition. Lippincott Williams \& Wilkins, pp1280-1311, 2007. 
7. Hussey DH: Carcinoma of the prostate. In: Textbook of Radiotherapy. Fletcher GH (ed). 3rd edition. Lea \& Febiger, Philadelphia, pp894-914, 1980.

8. Pilepich MV, Prasad SC and Perez CA: Computed tomography in definitive radiotherapy of prostatic carcinoma, part 2: Definition of target volume. Int J Radiat Oncol Biol Phys 8: 235-239, 1982.

9. Boehmer D, Maingon P, Poortmans P, Baron MH, Miralbell R, Remouchamps V, Scrase C, Bossi A and Bolla M; EORTC radiation oncology group: Guidelines for primary radiotherapy of patients with prostate cancer. Radiother Oncol 79: 259-269, 2006

10. Bentzen SM, Constine LS, Deasy JO, Eisbruch A, Jackson A, Marks LB, Ten Haken RK and Yorke ED: Quantitative analyses of normal tissue effects in the clinic (QUANTEC): An introduction to the scientific issues. Int J Radiat Oncol Biol Phys 76: (3 Suppl) S3-S9, 2010

11. Dearnaley DP, Hall E, Lawrence D, Huddart RA, Eeles R, Nutting CM, Gadd J, Warrington A, Bidmead M and Horwich A: Phase III pilot study of dose escalation using conformal radiotherapy in prostate cancer: PSA control and side effects. Br J Cancer 92: 488-498, 2005.

12. Khoo VS, Bedford JL, Webb S and Dearnaley DP: Class solutions for conformal external beam prostate radiotherapy. Int J Radiat Oncol Biol Phys 55: 1109-1120, 2003.

13. Smith WL, Lewis C, Bauman G, Rodrigues G, D'Souza D, Ash R Ho D, Venkatesan V, Downey D and Fenster A: Prostate volume contouring: A 3D analysis of segmentation using 3DTRUS, CT, and MR. Int J Radiat Oncol Biol Phys 67: 1238-1247, 2007.

14. Villeirs GM, Van Vaerenbergh K, Vakaet L, Bral S, Claus F, De Neve WJ, Verstraete KL and De Meerleer GO: Interobserver delineation variation using CT versus combined CT + MRI in intensity-modulated radiotherapy for prostate cancer. Strahlenther Onkol 181: 424-430, 2005.

15. Creak A, Hall E, Horwich A, Eeles R, Khoo V, Huddart R, Parker C, Griffin C, Bidmead M, Warrington J and Dearnaley D: Randomised pilot study of dose escalation using conformal radiotherapy in prostate cancer: Long-term follow-up. Br J Cancer 109: 651-657, 2013

16. Bolla M, van Poppel H, Collette L, van Cangh P, Vekemans K, Da Pozzo L, de Reijke TM, Verbaeys A, Bosset JF, van Velthoven R, et al: Postoperative radiotherapy after radical prostatectomy: A randomised controlled trial (EORTC trial 22911). Lancet 366: 572-578, 2005.

17. Swanson GP, Hussey MA, Tangen CM, Chin J, Messing E, Canby-Hagino E, Forman JD, Thompson IM and Crawford ED; SWOG 8794: Predominant treatment failure in postprostatectomy patients is local: Analysis of patterns of treatment failure in SWOG 8794. J Clin Oncol 25: 2225-2229, 2007.

18. Wiegel T, Bottke D, Steiner U, Siegmann A, Golz R, Störkel S, Willich N, Semjonow A, Souchon R, Stöckle M, et al: Phase III postoperative adjuvant radiotherapy after radical prostatectomy compared with radical prostatectomy alone in pT3 prostate cancer with postoperative undetectable prostate-specific antigen: ARO 96-02/AUO AP 09/95. J Clin Oncol 27: 2924-2930, 2009.

19. Pilepich MV, Winter K, John MJ, Mesic JB, Sause W, Rubin P, Lawton C, Machtay M and Grignon D: Phase III radiation therapy oncology group (RTOG) trial 86-10 of androgen deprivation adjuvant to definitive radiotherapy in locally advanced carcinoma of the prostate. Int J Radiat Oncol Biol Phys 50: 1243-1252, 2001

20. Pilepich MV, Winter K, Lawton CA, Krisch RE, Wolkov HB, Movsas B, Hug EB, Asbell SO and Grignon D: Androgen suppression adjuvant to definitive radiotherapy in prostate carcinoma-long-term results of phase III RTOG 85-31. Int J Radiat Oncol Biol Phys 61: 1285-1290, 2005.

21. Bolla M, Van Tienhoven G, Warde P, Dubois JB, Mirimanoff RO, Storme G, Bernier J, Kuten A, Sternberg C, Billiet I, et al: External irradiation with or without long-term androgen suppression for prostate cancer with high metastatic risk: 10-year results of an EORTC randomised study. Lancet Oncol 11: 1066-1073, 2010.

22. Denham JW, Steigler A, Lamb DS, Joseph D, Turner S, Matthews J, Atkinson C, North J, Christie D, Spry NA, et al: Short-term neoadjuvant androgen deprivation and radiotherapy for locally advanced prostate cancer: 10 -year data from the TROG 96.01 randomised trial. Lancet Oncol 12: 451-459, 2011.
23. Nguyen PL, Chen MH, Beard CJ, Suh WW, Renshaw AA, Loffredo M, McMahon E, Kantoff PW and D'Amico AV: Radiation with or without 6 months of androgen suppression therapy in intermediate- and high-risk clinically localized prostate cancer: A postrandomization analysis by risk group. Int $\mathrm{J}$ Radiat Oncol Biol Phys 77: 1046-1052, 2010.

24. Shipley WU, Verhey LJ, Munzenrider JE, Suit HD, Urie MM, McManus PL, Young RH, Shipley JW, Zietman AL, Biggs PJ, et al: Advanced prostate cancer: The results of a randomized comparative trial of high dose irradiation boosting with conformal protons compared with conventional dose irradiation using photons alone. Int J Radiat Oncol Biol Phys 32: 3-12, 1995

25. Pollack A, Zagars GK, Starkschall G, Antolak JA, Lee JJ, Huang E, von Eschenbach AC, Kuban DA and Rosen I: Prostate cancer radiation dose response: Results of the M. D. Anderson phase III randomized trial. Int J Radiat Oncol Biol Phys 53: 1097-1105, 2002.

26. Zietman AL, DeSilvio ML, Slater JD, Rossi CJ Jr, Miller DW, Adams JA and Shipley WU: Comparison of conventional-dose vs. high-dose conformal radiation therapy in clinically localized adenocarcinoma of the prostate: A randomized controlled trial. JAMA 294: 1233-1239, 2005.

27. Sathya JR, Davis IR, Julian JA, Guo Q, Daya D, Dayes IS, Lukka HR and Levine M: Randomized trial comparing iridium implant plus external-beam radiation therapy with external-beam radiation therapy alone in node-negative locally advanced cancer of the prostate. J Clin Oncol 23: 1192-1199, 2005.

28. Peeters ST, Heemsbergen WD, Koper PC, van Putten WL, Slot A, Dielwart MF, Bonfrer JM, Incrocci L and Lebesque JV: Dose-response in radiotherapy for localized prostate cancer: Results of the Dutch multicenter randomized phase III trial comparing 68 Gy of radiotherapy with 78 Gy. J Clin Oncol 24: 1990-1996, 2006.

29. Viani GA, Stefano EJ and Afonso SL: Higher-than-conventional radiation doses in localized prostate cancer treatment: A meta-analysis of randomized, controlled trials. Int J Radiat Oncol Biol Phys 74: 1405-1418, 2009.

30. Roach M III, Pickett B, Holland J, Zapotowski KA, Marsh DL and Tatera BS: The role of the urethrogram during simulation for localized prostate cancer. Int J Radiat Oncol Biol Phys 25: 299-307, 1993.

31. Liu YM, Ling S, Langen KM, Shinohara K, Weinberg V, Pouliot J and Roach M III: Prostate movement during simulation resulting from retrograde urethrogram compared with 'natural' prostate movement. Int J Radiat Oncol Biol Phys 60: 470-475, 2004.

32. Law ton CA, Michalski J, El-Naqa I, Buyyounouski MK, Lee WR, Menard C, O'Meara E, Rosenthal SA, Ritter M and Seider M: RTOG GU Radiation oncology specialists reach consensus on pelvic lymph node volumes for high-risk prostate cancer. Int J Radiat Oncol Biol Phys 74: 383-387, 2009.

33. Buwenge M, Marinelli A, Deodato F, Macchia G, Wondemagegnhu T, Salah T, Cammelli S, Uddin AFMK, Sumon MA, Donati CM, et al: Definition of fields margins for palliative radiotherapy of pancreatic carcinoma. Mol Clin Oncol 8: 715-718, 2018.

34. Morganti AG, Marinelli A, Buwenge M, Macchia G, Deodato F, Massaccesi M, Kigula-Mugambe J, Wondemagegnhu T, Dawotola D, Caravatta L, et al: Palliative two-dimensional radiotherapy of pancreatic carcinoma: A feasibility study. Tumori 99: 488-492, 2013

35. Buwenge M, Cilla S, Cammelli S, Macchia G, Arcelli A, Farina E, Frakulli R, Panni V, Wondemagegnhu T, Uddin AFMK, et al: Feasibility of 2D-conformal radiotherapy for pancreatic carcinoma. Oncol Lett 16: 5939-5945, 2018.

This work is licensed under a Creative Commons Attribution-NonCommercial-NoDerivatives 4.0 International (CC BY-NC-ND 4.0) License. 